\title{
A model of swādhyāya chikitsā for healthy mind and cognitive restructuring
}

HEMADRI K. SAO, ABHISHEK K. BHARDWAJ and GAURAV AGRAWAL

\begin{abstract}
Observation of present scenario indicates that the root cause of widely spread sufferings, distress and mental problems is certainly the distorted, directionless \& unfocused thinking. Those who are unable to manage themselves, always live in stress, that in its consequences leads the person towards mental disorders. For mental and physical fitness level one would have to learn the art of self-management; but it is possible only after knowing the self and refining it. Understanding one's own self and refining would require proper training, guidance and therapy. As there are not enough skillful guides, so one to one guidance is not possible. The solution for this is called "Swadhyaya chikitsa". It can play a vital role as a therapy. In modern psychology the assumptions of humanistic and existential (phenomenology) therapies come very close to it. It includes the cognitive restructuring in its process of therapy, but this therapy goes beyond normal cognitive therapy as the insights developed here are far more stable and naturally implemented.
\end{abstract}

Key words: Swadhyaya chikitsa, Mental Health and Cognitive restructuring.

Today all the mental health specialists of the world understand that the root cause of about $75 \%$ of all diseases is disturbed mental state. According to a survey in America, 20\% adults are affected by different mental problems (Pandya, 2004b). American writer Michel writes in his famous book 'Dirty Truth' that, twenty seven thousand people commit suicide in America every year (Bhatta, 2009). So it is clear that, people don't have control over their thoughts. Minds of the people have been too much polluted. Today man doesn't have a clear view point towards the life. He is emotionally alone, impatient and facing problem in making adjustment in the life. So there is an imbalance among his emotions, thoughts and behavior and this all is caused by the weakening of his cognitive system.

The cognitive system of the person is made up of his perception, memory, attention, thinking, learning, problem solving, reasoning, decision making etc. mental activities (Singh, 2006). The most important thing among these is thought process. As long as a person does not have clear and strong thought process, till then his cognitive system also not be fully developed and well adjusted. Truth is that our thoughts alone make us rise and fall. Yoga experts and psychologist both believe that only negative thoughts are responsible for all the mental disorders. Negative thoughts spoil the mind (Saraswati, 2005). Every day nature keeps on bombarding millions of negative thoughts and information on our mind and person is affected by all these and also enjoys it.

Lord Krishna explains the reason of mental problems and cognitive degradation in Gita (Gita2/62-63) - "The man dwelling on sense-objects develops attachment for them; from attachment springs up desire, and from desire (unfulfilled) ensues anger. From anger arises infatuation; from infatuation, confusion of memory; from confusion 
of memory, loss of reason; and from loss of reason one goes to complete ruin (Goyandka, 2007).

In the present time, everyone is struggling in a Mahabharata in his own mind (Brahmavarchas, 2008b). Like the western countries, psychiatry and psychotherapy are getting popular in India too, but problem of mind is still the same. According to Acharya Shriram Sharma, if psychiatry wants to solve the mental problems of human, then it must link up with spiritualism and yogic techniques (Pandya, 2004a).

Disturbed thoughts are the root cause of diseases and sadness (Brahmavarchas, 2007). So the thing that is most needed is to readjust the thought process, to clean the mental state, which is polluted by negative thinking and for this, swadhyaya therapy can be an extremely beneficial tool.

The aim of this article is to spread awareness in the world about swadhyaya chikitsa; so that, by using and implementing its procedure in the life, people may understand its power and manage their own self, their health and life.

\section{Swadhyaya \& Swadhyaya Chikitsa}

'Swadhyaya' is the art of knowing yourself. The real meaning of swadhyaya is 'to study the self' (Pandya, 2005a). Dr. Karambelker, commentator of Patanjali Yogsutra, says about the swadhyaya that, swadhyaya has two meanings- One is to study the holy religious books, second is self analysis of the behavior of body and mind (Karambelker, 2005).

According to Swami Jyotirmayananda, swadhyaya means repeated thinking about the nature of soul, but, in limited context, meaning of swadhyaya is to study the holy books for progress towards soul and chanting of your favorite mantra of God (Jyotirmayananda, 2000b).

Maharshi Patanjali has categorized swadhyaya in kriyayoga and he believes it to be helpful in attaining 'Samadhi'. In its deeper meaning, swadhyaya is a powerful effort for the reconstruction of mental structure (Pandya, 2009). Great philosopher Acharya Shriram Sharma said about swadhyaya- "One that can take away all our worries, can solve all our problems and doubts, and arouse the feeling of well-being for everyone, only that can be a true swadhyaya (Brahmavarchas, 1998a)." The continuous study of our own life is also a part of swadhyaya (Goyandka, 2006).

Swadhyaya therapy is based on in the principle of replacement of negative thoughts by positive ones. Through this formula, anyone can develop his personality by replacing his negative thoughts by positive ones. The great scholar Shishro said that the study of a good literature looks after a man and gives him patience in difficult times.

In the spiritual world, swadhyaya is given the place of a therapy. Swadhyaya is necessary for the psycho-immunity and refinement of thought process, since without the refinement of mind and thoughts, one cannot imagine a healthy body and civilized behavior. Swadhyaya first provides the mind healthy and then the life. Firstly, swadhyaya therapy refines the thought system and makes the realization of 'self' (Pandya, 2005b).

A working definition of Swadhyaya in modern context can be:

'Swadhyaya is a positive thought input into cognitive area to make it healthy and function properly.'

This definition describes the most of the characteristics of Swadhyaya. It's true that if we make our view-point healthy then all the dimensions of life become healthy automatically. Swadhyaya treats this very view-point and changes the way of looking (Pandya, 2005a). Whatever type of literature a man reads, his view-point becomes of the same type (Acharya, n.d.). As regular exercise is necessary to keep the body healthy; in the same way the swadhyaya of good books is necessary to keep the mind healthy (Dixit, 2009). 
Swadhyaya is a strong technique for making a great person. All the great people, scientists, saints of the world used to do regular swadhyaya. This was the reason because of which they could live the life happily and patiently even in the midst of all problems of the life. Swadhyaya is also a very good tool for the self-development. In the ancient times, Rishis definitely used to teach their disciples the sutra 'Swadhyayat Maa Pramadah'. This formula means 'never be lazy in increasing your capacities by swadhyaya'.

The device of thinking is called mind (Brahmavarchas, 1998a). The power of mind is based on thoughts. Whatever is the height of one's thoughts, same will be the level of his greatness and spiritual health.

\section{Process of Swadhyaya therapy}

Swadhyaya is the great process of sharpening of one's cognitive skills (Pandya, 2005b). There are four main steps of swadhyaya therapy -

1). First of all such classics and literature are chosen, that are created by people who had realized their own self. For e.g.- Upanishads, Gita, Vedas, books by Shri Aurovindo, Swami Vivekananda, Acharya Shriram Sharma etc., the biographies of martyrs, yoga, spirituality and books about life- management. 2). In the second step, we analyze ourselves with respect to those thoughts and try to understand where do we stand in comparison to the mental state describe in these books - with it, we also try to understand what we are thinking, what we are doing and what we should be thinking and what we should be doing. 3). In the third step, we make a strategy for rectifying our view- point. We make a complete plan for removing our troubles and working process for this plan is also ascertained. 4). In the fourth step, the new thoughts received from swadhyaya are adopted in our behavior completely, because without bringing these thoughts in our behavior, all this effort will be in vain (Pandya, 2005).
Swadhyaya not only nourishes various modalities of cognition but also helps them work better. The cognitive functions like perception, attention, decision making, learning and memory improve considerably by regular swadhyaya. Swadhyaya helps in improving the attention as it creates an optimal arousal state. This optimal arousal state is the reflection of the positive cognitive state where one is full of enthusiasm and is looking forward for achieving one's goal. A person with scattered thoughts and indecisive mind is always below the optimal attention level and cannot really filter out the unnecessary information overload; hence it also reduces other cognitive functions, as human cognitive capacities are quite limited. But a person following the swadhayaya is free from this, and knows what he is doing and what are its implications; so there is always a sense of certainty in him. Perception improves as the subject develops the tendency to perceive the important and useful stimulus from the environment. A positive mental state increases the perception of positive events and stimuli, and reduces the perception of negative, depressing and trivial things.

Swadhyaya works as a mental tonic. Swadhyaya brings an emotional maturity and develops emotional quotient considerably. The reason is simple; the person's way of looking at life changes considerably. His objectives towards the life change and become bigger. His way of looking and reaction to the events changes dramatically (Pandya, 2005a). It develops a mental and emotional strength. What swadhayaya does is that it improves the reaction time but reduces the reaction. This way he can not only deal with his own emotional turmoil effectively and quickly but also becomes a role model for others in his vicinity. This way he also helps to manage their emotional problems as well. Swadhyaya is a powerful cognitive therapy as it redefines the emotional and cognitive values; and all this happens naturally with the time from inside, 
without any external help and suggestion. New thoughts work like seeds, and once they take place they are bound to bring fruits after some time.

\section{Benefits of Swadhyaya}

In reality, regular swadhyaya refines the viewpoint. Swadhyaya inspires us to be an ideal. Swadhyaya is the key to the solutions of all our troubles (Acharya, 1964). By swadhyaya, person takes the good thoughts in his life and by bringing good thoughts in life alone removes the negative thoughts (Acharya, 2006). The benefits of swadhyaya therapy are as follows -

1). Swadhyaya brings the new thoughts that turn our way of thinking. The person's way of perception also changes; that helps the man in finding the right solution for his problems and in taking the right decisions (Saraswati, 2001). 2). When a person examines himself again and again by swadhyaya, then he understands his own self, he comes to know about his own hidden potentials that increases his creativity and confidence (Saraswati, 2001). 3). By swadhyaya one comes to know about his own real condition and his egoism slowly diminishes. According to Dr. J. Yogendra, "We decrease stress and stress related problems when we decrease our identification \& 'I' sense" (Yogendra, 1997). 4). Swadhyaya keeps a person away from mental disorders, worries \& grieves (Dixit, 2009). 5). It is seen that when mind is disturbed by worries and mental hard work then the study of good books naturally removes those worries and stress (Saraswati, 2001). 6). The person doing swadhyaya always keeps getting guidance. As and when things happen in life and guidance comes naturally (Brahmavarchas, 1998b). 7). Regular swadhyaya practitioner goes beyond the all grieves (Mahabharata- Shantiparva, Acharya, 1964). 8). Swadhyaya practitioner never feels loneliness (Brahmavarchas, 1998b). 9). Regular swadhyaya develops vivek i.e. right understanding. This is also helpful in developing the feeling of vairagya (non-attachment); thus person attains psycho-immunity. As in yoga, attachment alone is called the root cause of all the grieves (Barnwal, 2002).

\section{Experimental studies on swadhyaya}

There is a limited scientific research on the effectiveness of swadhyaya therapy. Few available findings are here:

In a recent Indian study (Effect of Swadhyaya on the Mental Health of the Elderly), 30 subjects (aged between 45 years and above) were selected from the Vanaprastha Ashram located in Haridwar, Uttarakhand. All of them were provided ten books written by Pt. Shriram Sharma Acharya (Shantikunj, Haridwar, India) for swadhyaya. Their mental health level was assessed using a reliable and valid psychological scale before and after two months period. After two months of swadhyaya, the significant change in their mental health was noted (Behera \& Kotnala, 2012). In another study, swadhyaya therapy with two months practice of Nada yoga and Pragya yoga vyayama was also found very useful in enhancing the level of mental health in the adolescents of ages ranging between 13 and 18 years (Kashyap, 2009).

\section{CONCLUSION}

In the light of wisdom of sages and available researches it can be concluded that by swadhyaya therapy one can refine his mental structure and make it healthier and richer by good thoughts. According to M. Vasudevan, "All we are the result of what we have thought" (Vasudevan, 2003).

"Thought power is the greatest power on the earth. As we think, so we become. Mind is the most mysterious instrument in the hands of the soul. One can evolve to unimaginable heights by directing the mental process towards that which is positive" (Jyotirmayananda, 2000a).

Our mind is like a super computer on which negative thoughts are always attacking like viruses. Swadhyaya is very necessary to protect our 
mind from these viruses. Swadhyaya like a powerful scanner scans the negative thoughts and replaces them by positive thoughts that make our minds illuminated. This way regular swadhyaya is like a panacea for removing mental weakness. Today there is a big need for thought management (vichar sanyam) and this is possible through swadhyaya alone, because by swadhyaya our mental energy starts getting concentrated and person feels himself energized. Hence, there is nothing better than swadhyaya for keeping our cognitive system immune from all the mental disorders (Pandya, 2005b).

HEMADRI K. SAO, PhD, Associate Professor \& HOD of Clinical Psychology, Dev Sanskriti Vishwavidyalaya, Haridwar, India; ABHISHEK K. BHARDWAJ, PhD, Scientist, Department of Yoga Research, Patanjali Yogpeeth, Haridwar, India; GAURAV AGRAWAL, PhD, Assistant Professor of Psychology, Dev Sanskriti Vishwavidyalaya, Haridwar, India.

\section{REFERENCES}

Acharya, S. S. (1964, February). Swadhyaya-aatma ka bhojan. Akhand Jyoti, 2, 14-15.

Acharya, S. S. (2006). Swadhyaya aur satsanga. Mathura: Yug Nirman Yojna, (pp. 1).

Acharya, S. S. (n.d.). Jivan jine ki kala. Mathura: Yug Nirman Yojana, (pp. 3-5).

Barnwal, S. L. (2002). Yog Aur Mansik Swasthya. Delhi, India: New Bhartiya Book Corporation, (pp. 140141).

Behera, S. \& Kotnala, A. (2012). Effect of swadhyaya on the mental health of the elderly. Indian Journal of Health and Wellbeing, 3(4), 1004-1006.

Bhatta, K. (2009). 'Virodhiyon ka jhooth' in Ayurved Mahavisheshank (annual issue). Aha! Zindagi, 5: 31.

Brahmavarchas (1998a). Aatmotkarsha ka aadhar gyan (Vol.. 58). Mathura, India: Akhand Jyoti Sansthan, (pp. 45).

Brahmavarchas (1998b). Sadhna se sidhi (Vol. 5). Mathura: Akhand Jyoti Sansthan, (pp. 6.6).
Brahmavarchas (2007). Vikrit chintan rog-shok ka mulabhuta karan. Mathura, India: Yug Nirman Yojna, (pp. 49).

Brahmavarchas (2008b). Dev sanskriti aur man ka vigyan. Haridwar, India: Dev Sanskriti University Publication, (pp.1).

Dixit, R. (2009, October 11). Swadhyaya evum satsanga. Danik Jagran (Hindi Newspaper), pp. 10.

Goyandka, H. (2006). Maharishi patanjalikrit yogdarshan. Gorakhpur, India: Gita Press, (pp. 33).

Goyandka, H. (2007). Shrimadbhagwadgita. Gorakhpur, India: Gita Press, (pp. 47).

Jyotirmayananda, S. (2000a). The art of positive thinking. Gaziabad, India: International Yog Society, (pp. 13).

Jyotirmayananda, S. (2000b). Yog of sexsublimation in truth \& nonviolence. Gaziabad, India: International Yog Society, (pp. 143).

Karambelker, P. V. (2005). Patanjal yog-sutra (2 ${ }^{\text {nd }}$ ed.).. Lonawala, India: Kaivalyadham (pp. 49).

Kashyap, S. (2009). Pragya yog vyayam, Nada yog tatha swadhyaya ka vidyarthiyon ke mansik swasthya tatha aashawadi-nirashawadi manovritti per prabhav. (Unpublished Ph.D. Thesis). Dev Sanskriti University, Haridwar (India).

Pandya, P. (2004b, July). Girta mansik swasthya, badhte manovikar. Akhand Jyoti, 7, 25.

Pandya, P. (2005a). Aadhyatmic chikitsa: ek samagra upchar paddhati. Haridwar, India: Sri Vedmata Gayatri Trust, (pp. 84).

Pandya, P. (2005b, March). Man aur jivan ki chikitsa karta hai swadhyaya. Akhand Jyoti, 3, 25.

Pandya, P. (2009, August). Aatmashodhan ka vigyan hai - niyam. Akhand Jyoti, 8, 39.

Pandya, P., (2004a, June). Ubhar raha hai manochikitsa ka ek naya tantra. Akhand Jyoti, 6, 8-10.

Saraswati, S. S. (2001). Satsang aur swadhyaya. Rishikesh, India: Divine Life Society. (pp. 82-109).

Saraswati, S. S. (2005). Mind- its mysteries and control. Rishikesh, India: Devine Life Society, (pp. 100).

Singh, A. K. (2006). Advanced general Psychology (5 $5^{\text {th }}$ ed.). Delhi, India: Motilal Banarasidas, (pp. 3).

Vasudevan, M. (2003). Emotional stress. New Delhi, India: Jaypee Brothers Medical Publishers, (pp. 294).

Yogendra, J. (1997). Yoga, stress and mental health. Mumbai, India: The Yoga Institute, (pp. 15). 